\title{
Assessing the value of sub-system technologies including Life Cycle alternatives
}

\author{
Alessandro Bertoni ${ }^{1}$, Ola Isaksson ${ }^{12}$, Marco Bertoni ${ }^{1}$, Tobias Larsson ${ }^{1}$ \\ ${ }^{1}$ Division of Functional Product Development, Luleå University of Technology, Luleå, Sweden \\ ${ }^{2}$ Volvo Aero Corporations, Trollhättan, Sweden
}

\begin{abstract}
Emerging from an industrial case study in the aerospace industry, the paper proposes an approach to evaluate subsystem technology concepts from a life cycle perspective. The approach is composed by 5 main phases that aims to drive product designers towards more value-oriented design decisions. It is shown how different life cycle alternatives, such as the selling of a Product-Service-System instead of a traditional product, deeply impact the value of design alternatives. The described approach has been developed in collaboration with industrial partners and represents a potential instrument to enhance value-driven product design.
\end{abstract}

Keywords:

Value Driven Design; Sub-System Technology; Life Cycle Engineering

\section{INTRODUCTION}

Making the correct choice in the preliminary design phase impacts the entire product life cycle in an order of magnitude that could span from making the product being a big success, to generating, instead, a total business failure [1]. This statement gains more and more relevance when the product is characterized by a long lifecycle, when the technology is highly capital-intensive and when later life cycle modifications imply huge expenditures in terms of money and labor. In the effort of being competitive in the globalized market, a common and intuitive strategy for companies is to cut costs while increasing structure efficiency [2]. However, this approach does not always lead to success. Cost competition does not ensure long-term value added, because of the real risk of engaging in a cost-based fight against market followers [3]. So far, what becomes a real target to any company who wants to lead, or keep on leading, the market, is to provide the highest value to the system in which the company is competing. This concept should be considered not only from the final product seller focusing on end user, but also by all those companies that are relevant business partners in the supply chain. Collopy [4] stated that a product to be successful should maximize the value generated for the customer and for the system; how the profit is then divided between companies is instead decided by the market.

To do so it is necessary to adopt a wide vision of the system, understanding how some changes in the sub-system impact on system level. This process is of relevant difficulty, because it implies the acquisition of an enormous knowledge about how the system works, and it needs therefore collaboration from upper-level companies, those could be reluctant to share core information about strategies and future actions with other product stakeholders. Nevertheless, in some business contexts all major companies of the supply chain can be interested in sharing this information. That is the case, for instance, of business deal implying revenue sharing, or concerning products embedding top-level technologies.

\section{MOTIVATION AND OBJECTIVES}

The main objective of the paper is to propose an approach to evaluate sub-system technology concepts from a life cycle perspective. Emerging from a real example the development of an aircraft engine component, the paper illustrates how the traditional functionality-performance analysis can be complemented by a more value-oriented assessment to enable more lifecycle-oriented decisions in a conceptual phase. The final aim of the paper is to contribute to the ongoing discussion about methods and tools to be used, in the preliminary design phase, to assess the value associated to a design alternative, in order to provide useful instruments to help design teams in choosing the solution that maximizes the value for the system.

\section{RESEARCH APPROACH}

The approach emerges from the analysis of real industrial problems rather then from a theoretical investigation. The initial problem statement has been defined in collaboration with major European industrial and academic partners in the aerospace sector, and has been further refined by interacting with an aircraft engine subsystem components provider. The approach for value assessment has been defined through workshops, physical meetings, informal interviews and company site visits. Such findings have been further analyzed in view of theory; improvements and implications have been proposed using as a reference the scenario created together with the industrial partner.

\section{DESIGN CONCEPTS ASSESSMENT IN A LIFE CYCLE PERSPECTIVE}

In an ideal scenario, companies should always select design concepts able to increase the added value for their customers and stakeholders. Being able to calculate a priori, in a transparent and repeatable way, the value of a given solution is, however, not a straightforward process. As stated by Anderson and Narus [5] remarkably few firms have the knowledge and capability to actually 
assess value and, by consequence, gain an equitable economic return for the value delivered to customers. This problem is further exacerbated when the product grows in complexity and when the development activity moves from a "system" to a "sub-system", or even "component", perspective. Here the need for a methodology that could help the design team in assessing the lifecycle value contribution of a concept becomes evident.

The concept of "value" radically change the way decisions are taken at all the levels of detail the design activity is conducted. The optimal design solution has not to be merely found at the intersection of the "Performance" and "Functionality" axes, rather a third dimension, encompassing the "life cycle option" perspective, as shown in Figure 1, should be considered. The adoption of a life cycle value creation perspective allows designers to judge different alternatives considering a more complete set of information that could lead to a more value-oriented choice.

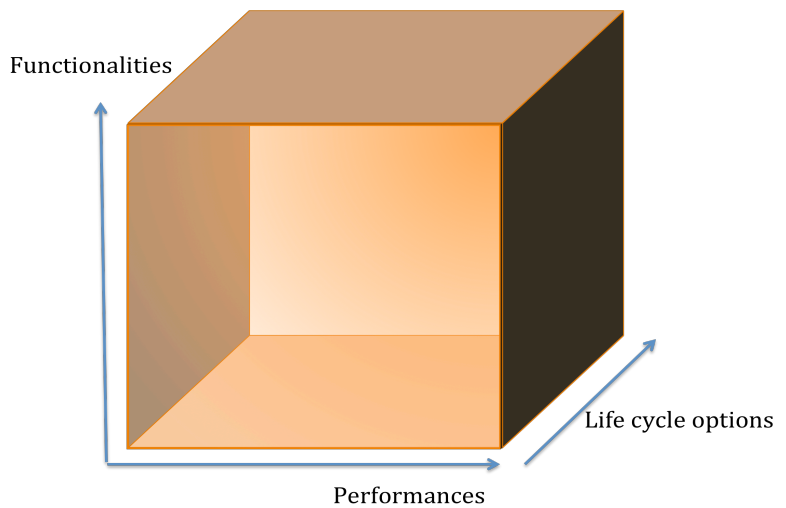

Figure 1: Choice dimensions.

To exemplify this concept, let's consider a sub-system manufacturer (company A) providing engine components to an aircraft engine manufacturer (company B). Company $A$ is therefore bound by contract agreements to satisfy given functionality and performance requirements. Mean Time Between Failure (MTBF, 20000 flight hours) and weight (70 kilos) represent two main requirements for a component under development. Design A1 has an MTBS of 20,010 hours and weights 69 kilos, while design A2 weighs 50 kilos and has a MTBF of 19,990 hours. The two alternatives are then identical in any other technical aspect. Although Design A2 does not meet the requirements, is really $A 1$ better than $A 2$ ?

Now consider that company B decides to change its selling policy, moving from the traditional selling of a product to providing life cycle commitment, keeping the ownership of the product along the life cycle until disposal. This choice has deep effects also on company
A that has now a wider set of information to work on when deciding, in a preliminary phase, which technology/component to be further developed. Company $A$, in fact, needs now not only to think in terms of performances and functionalities but also to consider, for example, how to make the components easier to maintain, or how to make them easier to re-use and recycle. The paper provides guidelines to drive designers toward a more value-oriented choice, allowing a divergent multi-dimension analysis, so to consider lifecycle options as basilar to define and assess the importance of the product main value drivers.

\section{LIFE CYCLE OPTIONS ANALYSIS: AN APPROACH}

The conceptual approach elaborated for sub-system technologies value assessment is composed by 5 main steps or activities, Figure 2 describes the approach and links each activity to the most relevant actors and stakeholders involved. To define the approach, a large cross-functional network of product stakeholders was established. This allowed the decomposition of the original problem into sub-problems reflecting product needs and requirements..

\subsection{Problem decomposition and requirements identification}

The requirements gathering process is usually a very complex affair and can represent a major obstacle to successful system development. It is argued that one reason for development projects poor performance, or even failure, is the mismatch between what expressed by the customers and what specified by the developers in terms of system requirements, a mismatch triggered by the differences in the cultural background of both sides [6].

Problem decomposition and requirements identification are the first steps of the methodology. Value assessment represents a big challenge for every design team, and thinking of facing it in a unique solution could lead to the rise of a big set of problems that could affect the results reliability. It is therefore inconvenient to consider it as a "unique box" to be solved; it is instead preferable to adopt a strategy of problem decomposition. [7]. Studies reveal that, analysis-synthesis-evaluation is a design method largely adopted and discussed in literature [8][9]. Analysis refers to the decomposition of the problem into sub problems; synthesis refers to the recomposition of sub problems in different ways; and evaluation refers to the test of the performance of new structures/systems [8]. As described by Simon [9] designers tend to decompose illstructured problems into several sub problems. Additionally stakeholders' expressed expectation needs to be collected by the design team. Designers should then interpret and reformulate the information acquired, in order to redefine expectations and validate them in a second round with stakeholders.

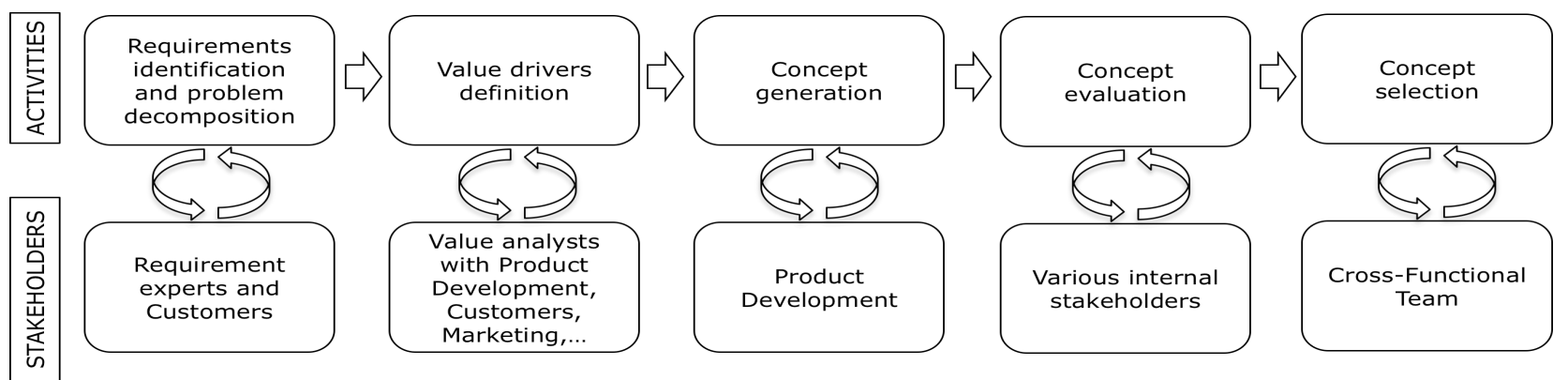

Figure 2: Value assessment process. 
Without losing the focus on expectations and adopting a life cycle perspective, the team should be able to translate the expectations into needs. A needs analysis should then be performed in order to highlight the conflicts between needs.

\subsection{Value drivers definition}

Once the problem has been decomposed and the relevant innovation topics have been defined, it is necessary to set a number of relevant and measurable value drivers for the value assessment. In order to facilitate both a quantitative and a qualitative evaluation, some value criteria are first defined. These represent the key fields on which the product directly or indirectly impacts. Each criteria clusters the value drivers that refer to the same field so to make easier a comparison between the different alternatives. To define coherent value drivers the team in charge of the activity needs to access to information regarding needs and requirements, defined in the previous step.

Moving from high-level value criteria [10], a cross-functional panel of expert is asked to formulate relevant value drivers for a given component under analysis. Value drivers are, in fact, specific instantiations of generic value criteria. The value drivers for a compressor blade, for instance, may significantly differ from those specified for an intermediate case, simply because they differ in terms of geometry, material, expected lifetime, etc., and because of different customer expectations.

A large number of stakeholders are involved in this part of the process. Product development and customers still plays a relevant role as in the requirements identification phase, but a wider vision on the system is needed. In order to avoid focusing too narrowly on the performance-functionality axes, members with knowledge from different backgrounds has to take part to the process. Introducing a system view on the future product, including in the decision team a wider set of stakeholders such as top management, marketing and production managers, could help to create a value assessment result more reliable. However team composed by heterogeneous actors with very different background could prove to be difficult to manage, since the members do not have a convergent perspective on their own specialization. Therefore there is the need of a figure that possesses knowledge about how the whole process works on a system level, having a deep understanding of the dynamics and of the knowledge generation sources that involve the product along all his life cycle. Hence the figure of the Value Analyst is introduced with the aim of providing a life cycle oriented perspective to the design team along all the product development process.

The process of defining value drivers can vary in different context; however experience and deep requirements analysis are fundamental instruments to help facing this activity, as far as focus groups and interviews are useful methodologies to reach the goal.

\subsection{Concepts generation}

The aim of conceptual design is to develop promising concepts. This requires generating a wide range of concepts, to prevent overlooking valuable concepts, and evaluating/selecting these soon enough, to restrict their number from getting too large to allow meaningful consideration. [11]

The new concepts can imply incremental improvement of existing products or radical innovation. In both case several methodologies are nowadays applied to enhance creativity and innovation in the design team. Some important examples, largely discussed in literature, that can differently be applied basing the choice on the final goal the design team wants to achieve. Brainstorming [12], is a group creativity technique designed to generate a large number of ideas for the solution of a problem, it is a valuable methodology when talking about radical innovation, it has the quality of enhancing creativity promoting the creation of a high number of ideas [13] that, however, could often fall outside the technological or practical constraint of a product. Introducing the Value Analyst in the process as a moderator in the brainstorming session could drive the team toward more value-oriented ideas. Delphi [14], is a structured interactive forecasting method which relies on a panel of experts and is performed anonymously in order to avoid bandwagon effect. It is a methodology oriented more on forecasting the future, and used for marketing and demand forecast analysis [15], so it is more suitable for concepts evaluation than for new concepts generation. TRIZ [16] is a problem solving, analysis and technology forecasting tool derived from the study of patterns of invention in the global patent literature [17]. TRIZ implies a structured approach on the problem providing general guidelines for system evolution but could be weak when focusing on detailed design. It focus on technological evolution not enhance a divergent value-oriented thinking. Focus groups [18] are interactive group setting where participants are free to talk with other group members. Organizing focus group allows the team to focus deeply on the problem, however it could limit creativity and create bandwagon effect among the group [19]. Focus groups are powerful methods if the discussion is well driven by moderator and if a collaborative spirit is spread among the group. The value analyst should play the moderator role keeping the attention of the group focused on the goal.

\subsection{Concepts evaluation}

The fourth step of the methodology is the concept evaluation. It represents a complex phase that can be structured as a process itself. During this phase is of primary importance the sharing of knowledge from the upper system levels. The project coordinator acts as a link between different stakeholders, both internal and external. Concept evaluation is the most critical phase in the methodology and has been addressed in detail in the 'Life cycle oriented concept evaluation process' chapter.

\subsection{Concept selection}

Last phase is concept selection, intended as an iterative process that does not always output a dominant concept immediately after the evaluation. A design alternative could prove to be more valuable in a value dimension and show to be weak under another point of view. A multi attribute decision-making problem [20] arises every time we need to decide between different complex design solutions. Nevertheless, it is important that the decision team can access all the data resulting from the evaluation in an easy and readable form, in order to have a complete set of information to base the decision upon. For this reason the concept selection phase is strictly linked to the value visualization. An easy and quick visualization of the value contribution of different alternatives can help decision-making team in choosing the best solution in a limited period of time. The amount of data to be evaluated in fact could be massive, generating therefore confusion, make people unable to judge the different alternatives from a wide value perspective. Current research efforts, in the value-driven design field, tend to focus on the development of a means to quickly visualize and evaluate one or more solutions in a rapid manner. [4]

\section{LIFE CYCLE ORIENTED CONCEPT EVALUATION PROCESS}

Assessing the value contribution of a solution is an activity that cannot be reduced to the a mere cost and revenue calculation; it is instead a combination of quantitative and often qualitative studies, which results needs to be weighted on the base of qualitative forecast and expectations. In general, there is currently no way to talk about better or worse with respect to an ad hoc aggregate of components. What is required is a process or rule for comparing designs to highlight what is better. 
Since a relevant part of the parameters cannot be evaluated in a coherent quantitative way, it is often better to recur to a qualitative evaluation based on the comparison between a baseline value, for example the minimum value requested by customer requirement, and a target value, that could represent the ideal parameter result. Considering the engine component example mentioned before, we fix a MTBF of 20000 hours and a weight of $70 \mathrm{~kg}$ as a baseline, and we fix at 50000 hours the targeted MTBF and 60 kilos the targeted weight we would assign a radically different value to the solutions. Qualitative ranking comparison is therefore necessary to run the value assessment.

A second critical aspect in the concept evaluation is the ability of correctly weighing the value drivers, to obtain a reliable final result. Depending, for example, from product nature, market requests, market forecast and company's objectives, some value drivers need to be considered more relevant than others. The weighting is obtained through the definition of a scale of values, e.g., form one to ten, or through a percentage estimation of the value drivers impact over the total product value.

The activity of weighting value drivers is a key step in the approach. It is basilar for a designer to know which characteristics, qualities, or performances, are critical. This is a phase where life cycle options play a crucial role. Different lifecycle perspective can deeply influence the relative importance of a value driver compared to another. Consider for example a traditional product selling structure, meaning that the product is sold in a unique solution, and a product/service system selling architecture, that implies keeping the ownership of the product along all its life, the two different company strategies hugely impact on product life cycle, creating the need to consider new value drivers, as well as different relative importance for the already existing drivers.

Figure 3 summarizes the process of concept evaluation highlighting activities, methodologies, actors and outputs.

The following paragraphs describe the four activities citing as a case study the evaluation of two different intermediate compressor cases (IMC) for aircraft engine. The evaluation took place considering two different life cycle perspectives, the traditional selling, and the selling of the Product/Service System (PSS) [21]. The case study involved a sub-system technology that needs to be integrated in the aircraft engine structure. Different selling strategies, and therefore different life cycle and ownership alternatives, for the aircraft engine, impact the value assessment in the IMC design phase.

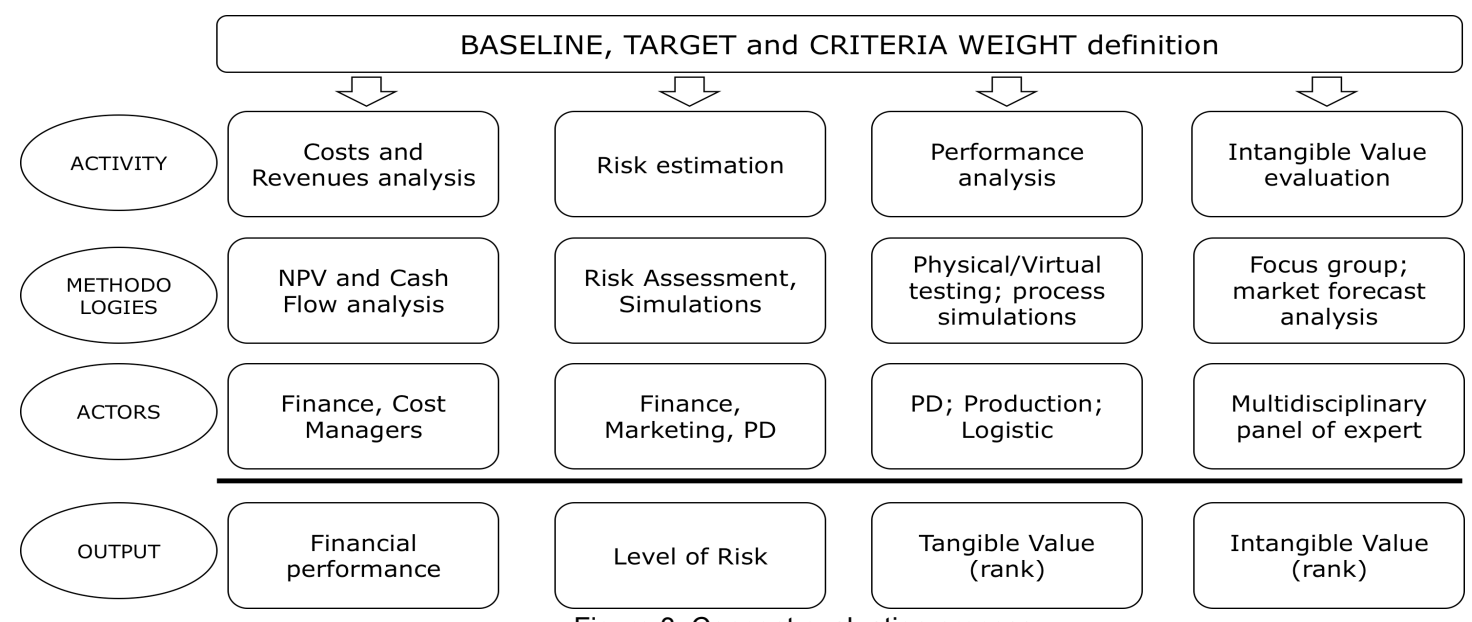

\subsection{Costs and revenues analysis}

Figure 3: Concept evaluation process.
The evaluation of costs and revenues concerns the estimation of the economical performance of an investment. Different methodologies are proposed by literature and broadly applied in industry. Between the most used it is possible to cite cash flow analysis [22], net present value and adjusted present value [23], internal rate of return calculation [24] and break-even analysis [25]. These activities are almost completely in charge of finance departments and cost managers.

Most of the concepts concerning costs and revenues analysis have been stated fifty or more years ago, however these instruments are currently still in use in many companies. Recently more methodology, i.e., the Modified Diatz Method [26], have been introduced in order to weigh individual cash flows by the amount of time that those cash flows are held, or absent, from the portfolio. These analysis, even if still valuable, provides as an output a value related only to the financial performance of the product, ignoring all other aspects related to the value perspective, i.e., the results are calculated in term of money, related to a single product/investment and the phenomena related to the whole value generation for the company are not considered. On a value driven design perspective cost and revenue analysis is still necessary but cannot be considered sufficient for a value assessment.

Considering the case study the adoption of a selling + maintenance and service policy implied the consideration of additional variables, such as spare part cost per year, service start-up costs, disassembly costs, recycling costs, remanufacturing cost per unit, service logistic costs, maintenance costs.

\subsection{Risk Estimation}

Every new product or component implies a certain level of risk. A large number of risk categories and a conspicuous set of methodologies is discussed in literature to estimate risk in new product development. Walker [27] presents a lightweight approach to technical risk estimation through a probability impact analysis. Altman and Saunders [28] propose an approach for credit risk measurement built around a mortality risk framework. Bangia et al. [29] describe a methodology for modeling liquidity risk in correlation with market risk measurement and management. Research is also focusing on regulatory risk measurement, exploring how a change in the regulation impacts the decision of an investment. Manteghini and Scarpa for example [30] describes how regulatory constraints affect a firm's investment choices when the firm has an option to delay investment. William [31] focuses on product development 
process design and on the response to market, technical and regulation risks, exemplifying with ten company case studies how different processes manage different risks.

Current methodologies used in industry are able to provide a satisfactory risk estimation in this phase of the process, hence no new methodology are proposed, but a combination off a set the techniques that could consider the broadest risk horizon is recommended.

Considering the risk analysis from the IMC design point of view, different weights for the risk dimensions needs to be considered. For example a PSS solution has been considered more critical in term of technical risk, since an originally bad design impacts the costs of maintenance and repair until the product disposal; or in terms of market risks, since the company doesn't know which will be the real response from the customers. In fact, considering the case of an IMC exclusively designed optimizing a PSS engine, the failure of the selling policy could cause big losses to the sub-system technology provider.

\subsection{Performance analysis}

Performance analysis is the most engineering intensive and technical activity of the process. Performance analysis provides quantitative data related to the in-field usage of the product. In case of a PSS, this category encompass also the value related to all the aspects concerning remanufacturing, maintenance, delivery and discard of the product.

Product performances are strictly linked to the requirements set in contracts or needed by the end user. Most of the time requirements fulfillment represents the basilar condition for a product to enter the market, especially in business-to-business situation.

Furthermore, performance analysis has to encompass not only performances relevant for the customer, but it is necessary to pay attention to a second performance dimension: the internal company performances. These performances are related to company organization and process structure e.g., process lead-time, process mean time between maintenance, process mean time between failure, machine saturation index, setup time. These aspects are measurable and needs to be taken into consideration when evaluating new design alternatives, in order to avoid indirect impacts on the overall company activity.

Different methodologies can be applied for product performance analysis. To test the 'in-field' performance of a product, physical and virtual testing, such as finite element analysis, are the most common methodologies in use. Instead, considering the internal performances, process simulation methodologies can provide a useful instrument to evaluate the response of the realization of a new product. Interesting examples of application can be found in Abdulmalek and Rajgopal [32] and in Smith et al. [33].

Considering an intermediate compressor case, the "in usage" performances need to be satisfied both for traditional product and PSS, in order to fit safety and customer requirements. However the PSS perspective can allow, in particular situation, the design of cheaper components with shorter life expectation, but that could be substituted more often, instead of choosing life-long and expensive components.

\subsection{Intangible Value evaluation}

Intangible value is a category that encompasses all those aspects not strictly related to product performances but that impact on the overall system. A various set of characteristics can be defined as providing intangible value. These dimensions are outside the technical horizon of the engineer, they cannot be easily captured [34]
An intangible value could be the relevance of the engineering solution in relation with the flexibility of the environment, in which it operates. Aspects to be taken into consideration are, for example, the degree of compatibility to the external environment and how much an unexpected modification impacts the product function. More undefined, but not less important value is the effect of a choice on brand acknowledgement or in new knowledge acquisition. These aspects cannot be immediately translated into tangible performance, but contribute to the generation of competitive advantage in the long run.

In the case study analysis, considering a PSS life cycle, aspect like new knowledge acquisition, continuous improvement enhancement, robustness to external constraint modification or brand acknowledgment, are important, and, by consequence, a big attention has been paid to them during the definition of value drivers weights.

\section{CONCLUSION}

The described approach represents a potential instrument to increase the awareness about requirements and value embedded in a design alternative.

In authors' belief the adoption of such a process for assessing the value of sub-system technology would help companies to move a step forward a value-driven design, granting good economic performance in the long run. Companies able to correctly assess the value of their sub-technologies, considering the value they provide to the system, would in fact maximize the economic return on their investment.

The advantage of the proposed approach is to increase the knowledge about the real value provided to the system by a subsystem technology, and take advantage form this since the preliminary design phase. Traditional cost or performance analysis doesn't possess such capability of looking to the value of a product from a system perspective.

The proposed methodology has been developed in collaboration with an industrial partner, acting as a components provider for aircraft engines. The approach has been validated through discussions and workshops together with other international partners in the aeronautical sector, collecting positive and constructive feedback. It does not pretend to be exhaustive neither to offer a final solution to the problem. It is instead open to discussion, improvement, and future research both inside and outside the aeronautical field.

Due to the complexity of the problem and the conspicuous need of data, it is difficult to foresee a large-scale application of the methodology in the short term. However we believe that knowledge sharing and communication are the key words to allow this approach being more and more applied in companies. In addition, the creation of automatic updates form company's database and models will mark a decisive improvement towards the automation of the process.

The authors are currently involved in studies aiming to capture, model and understand customers' and stakeholders' needs and expectations. Moreover some methodologies and tools to help teams making decision at a gate, as for example the LIVERY, Light Weight Visualizator, proposed by Bertoni [35], are currently object of research.

\section{ACKNOWLEDGMENTS}

The research leading to these results has received funding from the European Union Seventh Framework Programme (FP7/2007-2013) under grant agreement $n^{\circ} 234344$ (www.crescendo-fp7.eu/). 


\section{REFERENCES}

[1] Browning, T.R.; Deyst, J.J.; Eppinger, S.D., Whitney, D.E. (2002): Adding value in product development by creating information and reducing risk, IEEE Trans Eng Management, Vol. 49, Iss. 4, pp. 443-458.

[2] Stahl, J.M.; Grigsby, D.W. (1997): Strategic Management, Blackwell Publishing,

[3] Levitt, T. (1966): Innovative Imitation, Harward Business Review, Vol. 44, pp. 63-70.

[4] Collopy, P.; Hollingswort, P. (2009): Value Driven Design, in: Proceedings of 9th AIAA Aviation Technology, Integration, and Operations Conference, Hilton Head, South Carolina.

[5] Anderson, J.C.; Narus, J.A. (1998): Business Marketing: Understand What Customer Value, Harvard business review.

[6] Al-Karaghouli, W.; Alshawi, S.; Fitzgerald, G. (2005): Promoting requirement identification quality: Enhancing the human interaction dimension, in: Journal of Enterprise Information Management, Vol. 18, Iss: 2, pp.256 - 267.

[7] McCormick, W.; Scweitzer, P.; White, T. (1972): Problem Decomposition and Data Reorganization by a Clustering Technique, in: Operations Research, Vol. 20, No. 5, pp. 9931009

[8] Jones, C.J. (1992): Design Methods 2nd edition, Van Nostrand Reinhold, New York.

[9] Simon, H.A. (1973): The structure of ill-structured problems, in: Artificial Intelligence, Vol 4, pp 181-200.

[10] Bertoni, M.; Eres, H.; Isaksson, O. (2011): Criteria for assessing the value of Product Service System design alternatives: an aerospace investigation, submitted to $3^{\text {rd }}$ CIRP IPS ${ }^{2}$ conference, May 5th $-6^{\text {th }}$, Braunschweig, Germany.

[11] Liu, Y.C.; Chakrabarti, A.; Bligh, T. (2003): Towards an 'ideal' approach for concept generation, in: Design Studies, Vol. 24, Iss. 4, pp. 341-355.

[12] Osborn, A.F. (1963) Applied imagination: Principles and procedures of creative problem solving (Third Revised Edition),New York, NY, Charles Scribner's Son.

[13] Rawlinson, J.G. (1986): Creative Thinking and Brainstorming, gowerpublishing, UK.

[14] Linstone, H.A.; Turoff, M. (1975): The Delphi method: Techniques and applications, Addison-Wesley Publishing, Massachusetts.

[15] Rowe, G; Wright, G. (1999): The Delphi technique as a forecasting tool: issues and analysis, in: International Journal of Forecasting, Vol. 15, Iss. 4, pp. 353-375.

[16] Altshuller, G. (1999) The Innovation Algorithm: TRIZ, Systematic Innovation and Technical Creativity, original copyright 1973, published by Technical Innovation Center Worcester, Massachusetts.

[17] Hua, Z.; Yang, J.; Coulibaly, S.; and Zhang, B. (2006): Integration TRIZ with problem-solving tools: a literature review from 1995 to 2006, in: International Journal of Business Innovation and Research, Vol. 1, pp. 111-128.

[18] Kitzinger, J. (1995): Qualitative research: introducing focus groups, in: British Medical Journal, Vol. 311, No. 7000.

[19] Asch, S.E. (1955): Opinions and social pressure, in: Scientific American, Vol. 193, pp. 31-35.
[20] Dyer, J.; Fishburn, P.; Steuer, R.; Wallenius, J.; Zionts, S. (1992): Multiple Criteria Decision Making, Multiattribute Utility Theory: The Next Ten Years, in: Management Science, Vol. 38, No. 5, pp. 645-654.

[21] Baines, T.S.; Lightfoot, H.W.; Evans, S.; Neely, A.; Greenough, R.; Peppard, J.; Roy, R.; Shehab, E.; Braganza, A.; Tiwari, A.; Alcock, J.R.; Angus, J.P.; Bastl, M.; Cousens, A.; Irving, P.; Johnson, M.; Kingston, J.; Lockett, H.; Martinez, V.; Michele, P.; Tranfield, D.; Walton, I.M.; Wilson, H. (2007): State-of-the-art in product-service systems, in: Proceedings of the Institution of Mechanical Engineers, Part B: Journal of Engineering Manufacture. Vol. 221, No. 10.

[22] Bodenhorn, D. (1964): A Cash-Flow Concept of Profit, in: The Journal of Finance, Vol. 19, No. 1, pp. 16-31

[23] Robichek, A.; Myers, S. (1966): Conceptual Problems in the Use of Risk-Adjusted Discount Rates, in: The Journal of Finance, Vol. 21, No. 4, pp. 727-730.

[24] Turvey, R. (1963): Present Value Versus Internal Rate of Return-An Essay in the Theory of the Third Best, in: The Economic Journal, Vol. 73, No. 289, pp. 93-98

[25] Vickers, D. (1960): On the Economics of Break-Even, in: Accounting Review, Vol. 35, No. 3, pp. 405-412.

[26] Feibel, B.J. (2003): Investment Performance Measurement, Wiley, New York.

[27] Walker, R. J.; Holmes, R.; Hedgeland, I.; Kapur, P.; Smith, A. (2006): A Lightweight Approach to Technical Risk Estimation via Probabilistic Impact Analysis, in: Proceedings of ICSE Workshop on Mining Software Repositories, Shanghai, China, pp. 98-104.

[28] Altman, E.; Saunders, A. (1997): Credit risk measurement: Developments over the last 20 years, in: Journal of Banking \& Finance, Vol. 21, Iss. 11-12, pp. 1721-1742.

[29] Bangia, A.; Diebold, F.; Schuermann, T.; Stroughair, J. (2008): Modeling Liquidity Risk with Implications for Traditional Market Risk Measurement and Management, NYU Working Paper No. FIN-99-062.

[30] Panteghini, P.; and Scarpa, C. (2003): Irreversible Investments and Regulatory Risk, CESifo Working Paper Series No. 934.

[31] William, D. (2003): Product development process design: improving development response to market, technical, and regulatory risks, in: Engineering Systems Division PhD thesis, Massachusetts Institute of Technology.

[32] Abdulmalek, F.A.; Rajgopal, J. (2007): Analyzing the benefits of lean manufacturing and value stream mapping via simulation: A process sector case study, in: International Journal of Production Economics, Vol. 107, Iss. 1, Special Section on Building Core-Competence through Operational Excellence, pp. 223-236

[33] Smith, J.S.; Wysk, R.A.; Sturrock, D.T.; Ramaswamy, S.E.; Smith, G.D.; Joshi, S.B. (1994): Discrete event simulation for shop floor control, in: Proceedings of Winter Simulation Conference, pp. 962- 969.

[34] Steiner, F.; Harmor, R. (2009): The Impact of Intangible Value on the Design and Marketing of New Products and Services: An Exploratory Approach, in: Proceedings of PICMET 2009, Portland, Oregon USA.

[35] Bertoni, A.; Bertoni, M.; Isaksson, O. (2011): Communicating the value of PSS design alternatives using color coded CAD models, submitted to $3^{\text {rd }}$ CIRP IPS ${ }^{2}$ Conference, May 5th 6 th, Braunschweig, Germany. 